\title{
THE REJECTION OF SKIN HOMOGRAFTS IN THE NORMAL HUMAN SUBJECT. PART I. CLINICAL OBSERVATIONS *
}

\author{
By DAVID C. MARSHALL, ELI A. FRIEDMAN, DONALD P. GOLDSTEIN, \\ LAURENCE HENRY AND JOHN P. MERRILL $\dagger$
}

\author{
(From the Departments of Surgery, Medicine, and Pathology, Peter Bent Brigham Hospital \\ and Harvard Medical School, Boston, Mass.)
}

(Submitted for publication September 7, 1961; accepted October 30, 1961)

Since Medawar's now classic description of the immunology of homograft rejection in the rabbit, most knowledge of the process has been gained from the laboratory animal. Medawar demonstrated that, after the rejection of an initial skin homograft, any subsequent exposure of the recipient to skin from the same donor resulted in accelerated rejection, a process he termed the "second-set" phenomenon $(1,2)$. Although many others had noted such a sequence [Holman, working with human skin in 1924 (3), and Woglom with animal tumors in 1929 (4)], it was Medawar who convincingly ascribed an immunologic cause to the process. Earlier reports from this hospital have dealt with homograft rejection in uremics (5), and other investigators have reported studies in burned patients $(6,7)$, and in those suffering from agammaglobulinemia (8) and Hodgkin's disease (9-11) -all clinical states known to be accompanied by altered immunologic reactivity.

Because it is difficult to establish careful controls in such experimental groups, we have extended and altered the methods reserved for the laboratory animal, in order to have the opportunity to study healthy, adult, ambulatory volunteers. Converse and Rapaport (12) and Rapaport, Thomas, Converse and Lawrence (13) recently utilized such techniques in the human subject and their work served as background for much of this present study. Previous work in this laboratory has demonstrated that, after skin homograft re-

* Parts I and II of this study were supported in part by grants from the National Heart Institute (HTS-5274 and H-1771); a contract with the U.S. Army Medical Research and Development Command (DA-49-193-MD2061); by the American Heart Association; and by the Surgeon-in-Chief's Fund, Peter Bent Brigham Hospital.

† Investigator, Howard Hughes Medical Institute. Supported by USPHS Grant H-444(C9) and by a contract with the U. S. Army Medical Research and Development Command (DA-49-007-MD-429). jection, the human subject manifests cutaneous hypersensitivity to intradermal challenges of donor peripheral leukocytes (14). Before investigating problems related to this finding it was necessary to establish our clinical and microscopic criteria for homograft rejection in the healthy human subject. As the literature is deficient in this information, the present study was undertaken to record accurately the histology and concurrent gross appearance of rejecting skin homografts by daily serial biopsies and photographs. The scope of this work includes what has been described by Medawar as "first-set" rejection, "accelerated" or "second-set" rejection (1), and the more recently described "white-graft" rejection (15).

\section{MATERIALS AND METHODS}

Selection of subjects. All subjects were ambulatory adult male volunteers aged 21 to 60 years and were actively employed throughout the duration of the experiment. None had a previous history of blood transfusions or skin grafts, hepatitis or jaundice, syphilis or malaria, anemia, bleeding diatheses, autoimmune disease, or untoward reaction to procaine. Each received a physical examination, had his blood typed, and was accepted only after at least two physicians had agreed that the subject was in good health. The volunteers received no remuneration, but each was fully informed of the nature and extent of the study.

Technique of experimental skin grafting in the human subject. In experimental skin grafting of healthy, ambulatory volunteers there are certain considerations that are inconsequential in the laboratory animal. The graft must be placed so as to permit maximal immobilization. It must be located so as to facilitate frequent observations, biopsies, and dressing changes. Finally, and most important, if one is to attain the willing cooperation of the subject, the graft must not interfere with his daily activities, and the final scar should be as small as possible and in an inconspicuous area. We have found that the site best meeting both these surgical and cosmetic demands is the medial aspect of the upper arm.

Because the initial surgical procedure involves from two to four subjects, the sterile technique and the time 
element ( 1 to 3 hours) are best handled by two operators. After infiltration of the area with 1 per cent procaine (in solution with $1 / 1,000$ epinephrine), a full-thickness, square piece of skin is excised with a no. 15 blade. The desirable plane of incision is one that leaves the undersurface of the graft with a "pigskin" appearance. Subsequent defatting of the graft is unnecessary if it is cut properly initially. We believe that the more trauma the skin sustains at this stage, the more likely is ecchymosis to occur later (Figures 6,7). While awaiting transfer the excised skin is kept moist in a saline sponge. Temporary pressure over the bed controls most bleeding; ligation of bleeding points is unnecessary and undesirable. The grafts are sutured into place with 5-0 nylon, ${ }^{1}$ with either a continuous or interrupted stitch. During the first 2 weeks of frequent dressing changes, it is most satisfactory to cover the wound with a nonadherent plastic dressing (Telfa). After rejection takes place the granulating bed is better covered with fine-mesh gauze. At all times a bulky gauze pad is held in place over the site by an elastic pressure bandage. Adhesive tape is avoided because of the frequency of skin irritation. For those patients who are only donating skin, the donor sites are covered with a split-thickness graft taken from a nearby area. A second method we have recently used in obtaining small pieces of skin is to excise a $1 \times 3$ to $4 \mathrm{~cm}$ strip of skin, undermine the wound edges, and close it primarily.

Sutures are removed in 7 to 10 days unless the grafts are being biopsied. If this is the case, the sutures must remain in place during the period of biopsy, because the resultant reduction in area of the graft produces undue tension at its junction with the host. During the period of observation there is no return of pain sensitivity (even in the autograft), and anesthesia is unnecessary for biopsy so long as the bed is avoided. For biopsy, a 5- to 8-mm ellipse of skin is excised and the defect closed with a cuticular stitch (Figure 8). If the graft bed is to be sampled, infiltration anesthesia is carried out by obliquely inserting the hypodermic needle into the host skin at the edge of the graft and directing it deeply, toward the center of the bed. Despite the early handling of these grafts, technical failure is rare, and no significant infections have been encountered.

Preparation of the peripheral leukocyte extracts by dextran-sedimentation and the administration and interpretation of the intradermal skin test are completely described in an earlier report (16).

Plan of experiment. Three pairs of subjects each received over a period of time three separate exchanges of skin. The donor-recipient partners in each pair had no known familial relationship to each other. Each set of grafts consisted of a homograft, always from the same donor and, as a surgical control, one autograft. The second application of grafts was timed as close as possible to 14 days after placement of the first set in an attempt to obtain a white graft. The third exchange of grafts took place 4 weeks or more after placement of the

${ }^{1}$ Ethicon Inc., Somerville, N. J. first set in the hope of producing accelerated rejection of a vascularized graft. All grafts were photographed and biopsied at intervals from postoperative Day 1 until rejection was grossly terminated.

First-set grafts were placed on the left arm, the autograft always being 2 to $3 \mathrm{~cm}$ distal to the homograft. Second- and third-set grafts were both on the right arm. The first four grafts were $2.5 \times 5 \mathrm{~cm}$ in size, but thereafter the remaining 38 grafts were $2.5 \mathrm{~cm}$ square.

Within 2 weeks after the third set of grafts, the recipients received intradermal injections of donor and autologous white cells.

Definition of terms. "First-set" rejection describes that sequence of events by which a recipient destroys a homograft during his first encounter with tissue from that donor. "White graft" applies to the type of rejection that occurs in a homograft which is placed on such a highly immune host that the graft does not achieve even transient vascularization. "Accelerated" rejection applies to any vascularized graft that is destroyed in a significantly shorter time than the previously applied first-set graft. Both the white graft and accelerated rejection might rightfully be termed second-set rejections. The difference depends basically on the interval between its application and that of the first-set graft. "Rejection span" refers to that period of time from the onset of rejection (as described below) to the final destruction of the graft. The end point is determined by necrosis of more than 50 per cent of the graft area, or by the absence of bleeding on biopsy.

\section{EXPERIMENTAL RESULTS}

Of a total of 42 grafts of all types in this series, there were only two surgical failures (one autograft and one homograft; a surgical technical success rate of 95 per cent; see Table I). These failures were due to hemorrhage from the bed and caused no confusion. No significant infections occurred, although at the end of 8 to 9 days of repeated biopsies, the first-set autografts and homografts in the first pair (V.R. and R.B.) had some superficial sepsis without regional adenopathy or temperature elevation. Because of this, in the next two pairs of subjects duplicate homografts were put in place, only one of which was biopsied initially. On postoperative day 7 , the reserve homograft was sampled as well as the first so that we might check histologically the influence of biopsy on the course of immunologic destruction. Both grossly and microscopically, each of the pairs of homografts ran nearly parallel courses, and it was felt that repeated biopsy at most hastened the end of graft survival by 1 day. This was further supported by the observation that the autografts, al- 
TABLE I

First day of vascularization of grafts as determined by onset of bleeding on biopsy

\begin{tabular}{|c|c|c|c|c|}
\hline \multirow[b]{2}{*}{ Subject } & \multirow{2}{*}{$\begin{array}{l}\text { Blood } \\
\text { groups }\end{array}$} & \multirow{2}{*}{$\begin{array}{l}\text { Number } \\
\text { of sets }\end{array}$} & \multicolumn{2}{|c|}{$\begin{array}{c}\text { First day of } \\
\text { vascularization }\end{array}$} \\
\hline & & & Auto & Homo \\
\hline V.R. & $\mathrm{O}+$ & $\begin{array}{l}1 \\
2 \\
3\end{array}$ & $\begin{array}{l}4 \\
2 \\
F\end{array}$ & $\begin{array}{l}4 \\
4^{*}\end{array}$ \\
\hline R.B. & $\mathrm{O}+$ & $\begin{array}{l}1 \\
2 \\
3\end{array}$ & $\begin{array}{l}2 \\
2 \\
2\end{array}$ & $\underset{2}{2}+$ \\
\hline L.H. & $\mathrm{O}+$ & $\begin{array}{l}1 \\
2 \\
3\end{array}$ & $\begin{array}{l}1,2 \\
3 \\
1\end{array}$ & $\begin{array}{c}1,1 \\
1\end{array}$ \\
\hline C.J. & $A+$ & $\begin{array}{l}1 \\
2 \\
3\end{array}$ & $\begin{array}{l}1,1 \\
3 \\
1\end{array}$ & $\begin{array}{c}4,4 \\
1\end{array}$ \\
\hline R.H. & $\mathrm{O}+$ & $\begin{array}{l}1 \\
2 \\
3\end{array}$ & $\begin{array}{l}3 \\
2 \\
2\end{array}$ & $\begin{array}{c}3, F \\
W \\
2\end{array}$ \\
\hline W.S. & $A+$ & $\begin{array}{l}1 \\
2 \\
3\end{array}$ & $\begin{array}{l}3 \\
2 \\
2\end{array}$ & $\begin{array}{l}3,3 \\
W \\
W \ddagger\end{array}$ \\
\hline Mean & & & 2.1 & 2.5 \\
\hline
\end{tabular}

* Timed to produce a white graft; actually was accelerated rejection; $\mathrm{W}=$ white graft $; \mathrm{F}=$ technical failure.

$\dagger$ Brief, minimal vascularization, then typical course of white graft.

$\ddagger$ Timed to produce accelerated rejection; actually was white graft.

though equally frequently biopsied; were uniformly successful, except for the one failure mentioned above.

The most reliable index of vascularization of a graft is the presence of immediate bleeding when incision is carried to the depth of the dermis (Figure 8). Prior to the onset of the graft-host vascular anastomosis, when the entire thickness of the skin graft was incised, only serum was encountered at the graft-bed interface. With this criterion there was no discernible difference in the time of onset of vascularization between autografts and homografts, an observation well documented by others $(1,12,17)$. The time of onset of bleeding upon incision in all sets of vascularized grafts ranged from 1 to 4 days (mean, 2.3 days) in both autografts and homografts (see Table I). Blanching of the graft on pressure with rapidity of capillary return was helpful in assessing the vascular status of grafts in V.R. and R.B. (Figure 4) and correlated well with onset of bleeding.
However, this was not a reliable sign in the skin of Negro patients, as in the latter two pairs of subjects.

First-set grafts. Many criteria have been used to determine the onset of rejection in the homograft. Dilatation of the capillary bed as seen through the stereomicroscope was reported by Converse and Rapaport as the first sign (12). Others have noted at varying times the gross appearance of cyanosis, edema, and surrounding erythema. Many have relied solely on the microscopic infiltration of the graft with mononuclear cells and the amount of surviving epithelium (18). In this study it was noted that the first observation of edema in a vascularized graft correlated precisely (Figures 1-5) with the histologic arrival of perivascular round cells (see Table II). This edema is to be distinguished from that which is present in the immediate postoperative period before a lymphatic drainage is established, a process described by Scothorne (19).

In the six subjects with first-set grafts, the first day of rejection varied from 6 to 8 (mean, 6.7). Specific individual variation occurred, some subjects giving a rapid, violent rejection completed by Day 11, while others slowly deteriorated up to Day 14 (Figure 9). The mean rejection span was 5.6 days. As rejection terminated, a black eschar was formed, followed by typical granulation tissue in the graft bed (Figure 10). Healing was by the formation of normal scar tissue.

Surrounding erythema is not a reliable sign for first-set rejection because the suture reaction around the autograft controls often produced identical inflammation.

White graft. The first two subjects underwent the second grafting on Day 19 after the first set,

TABLF, II

Rejection course of first-set homografts

\begin{tabular}{lllll}
\hline \hline & $\begin{array}{c}\text { First } \\
\text { day of } \\
\text { vascu- } \\
\text { lariz- } \\
\text { ation }\end{array}$ & $\begin{array}{c}\text { First } \\
\text { day of } \\
\text { edema }\end{array}$ & $\begin{array}{c}\text { Day of } \\
\text { termi- } \\
\text { nation }\end{array}$ & $\begin{array}{c}\text { Rejec- } \\
\text { tion } \\
\text { span }\end{array}$ \\
\hline Subject & 4 & 6 & 10 & 4 \\
V.R. & 4 & 6 & 14 & 4 \\
R.B. & 2 & 7 & 11 & 4 \\
L.H. & $\mathbf{4}$ & 6 & 13 & 7 \\
C.J. & $\mathbf{4}$ & 7 & 12 & 5 \\
W.H. & $\mathbf{3}$ & $\mathbf{8}$ & 13 & $\mathbf{5}$ \\
M.S. & 2.8 & 6.7 & 12.1 & 5.6 \\
\hline
\end{tabular}


Fig. 1. L.H. Duplicate first-Set homografts AND AUTOGRAFTS ON THE DAY OF GRAFTING; NEGRO SKIN.

Fig. 2. L.H. Same as Figure 1, on postoperative DAY 4. Autografts and homografts are both well vascularized and, except for pigmentation differences, identical in appearance.

Fig. 3. L.H. Same as Figure 1, on postoperative DAY 9. Rejecting homografts on the left have marked edema and erythema. Multiple biopsy sites are seen in duplicate grafts.

Fig. 4.* Well vascularized AUtograft AND FIRST-SET HOMOGRAFT ON POSTOPERATIVE DAY 7, DEMONSTRATING BLANCHING ON PRESSURE; WHITE SKIN.

Fig. 5.* Same as Figure 4, on postoperative day 11. Note edema and erythema in rejecting homograft on right. Compared with Figure 4, the ecchymosis in the well vascularized autograft has nearly cleared.

Fig. 6. R.B. Autograph (LEFT) AND FIRST-SET hOMOGRAFT (RIGHT) AT TIME OF GRAFTING. Large-size grafts were soon found to be unnecessary and thereafter they were $2.5 \mathrm{sq} \mathrm{cm}$.

Fig. 7. R.B. Same as Figure 6, on postoperative DAY 2. Ecchymosis has reached a maximum in both grafts but has not interfered with vascularization (see Figure 8).

Fig. 8. R.B. Same as Figure 6. Technique of daily biopsy; anesthesia is unnecessary if the graft bed is avoided.

Fig. 9. R.B. Same as Figure 6, on postoperative DAY 12. The ecchymosis has cleared from the autograft. The homograft is edematous and erythematous but has not been completely rejected.

Fig. 10. R.B. Same as Figure 6, on postoperative DAY 25. Healthy granulation. tissue in the recipient bed following complete slough of the homograft. Note early contracture of the wound.
Fig. 11. R.B. Autograft And SECOND-SET HomoGRAFT (WHITE GRAFT) ON POSTOPERATIVE DAY 1, BEFORE EITHER IS VASCULARIZED.

Fig. 12. R.B. Same as Figure 11, on postoperative DAY 3. Autograft is showing signs of vascularization but "white graft" remains pale and flat.

Fig. 13. R.B. Same as Figure 11, on postoperative DAY 4. Autograft (right) bleeds briskly on biopsy, but this "white graft" has minimal bleeding only near the bed.

Fig. 14.* Classical "White graft" (Right) With ABSENCE OF BLEEDING EVEN ON INCISION OF FULL THICKNESS of SKIN. Autograft (left), although markedly ecchymotic, is normally vascularized.

Fig. 15. R.B. Autograft ANd THIRD-SET homograft (ACCELERATED REJECTION) ON POSTOPERATIVE DAY 3 (LABEL IN PHOTO IS INCORRECT), BOTH BLEEDING BRISKLY ON BIOPSY. Both are moderately ecchymotic.

Fig. 16. R.B. Same as Figure 15, on postoperative DAY 4. The homograft is undergoing accelerated rejection and reveals early edema.

Fig. 17. R.B. Same as Figure 15, on postoperative DAY 6. The homograft is already becoming necrotic and escharified. The ecchymosis is clearing from the autograft.

Fig. 18. R.B. Same as Figure 15, on postoperative DAY 7. The autograft is well vascularized as indicated by bleeding, but the rejecting homograft (left) produces only a sluggish flow on biopsy.

Fig. 19. R.O.H. A COMPARISON OF "White-GrafT" REJECTION AND ACCELERATED REJECTION. In the lower right is a rejecting third-set graft on postoperative Day 6 showing typical necrosis and eschar. Just above, in the center, is a rejecting white graft on postoperative day 36 , demonstrating the tan crust and absence of early wound contracture.

\footnotetext{
* Figures 4, 5, and 14 are photographs of subjects from a later series but are reproduced here because of their illustrative value.
} 

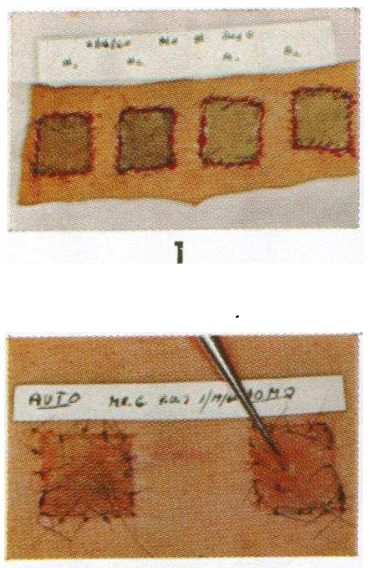

4
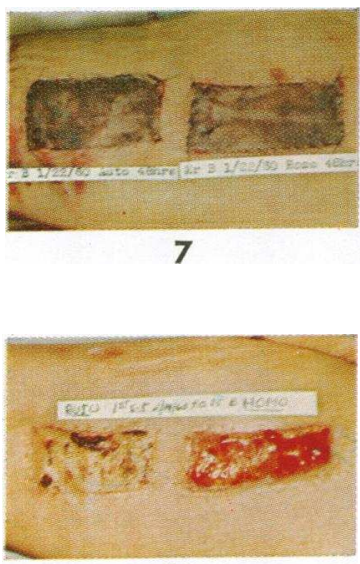

10

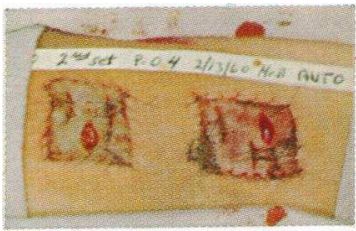

13



16
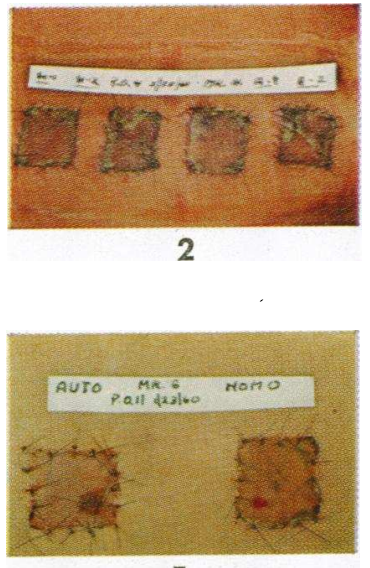

5
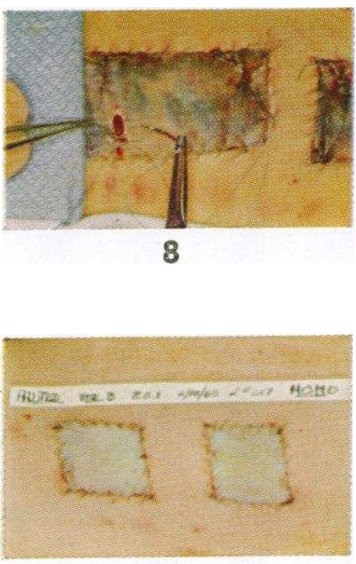

I1
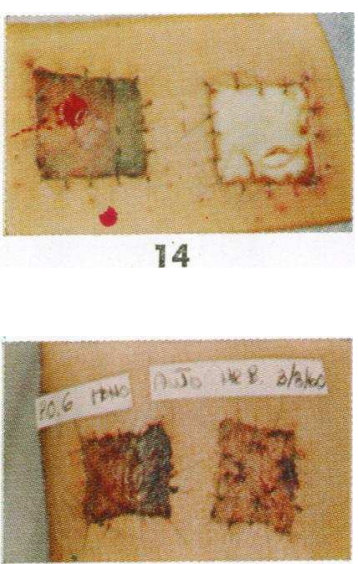

17

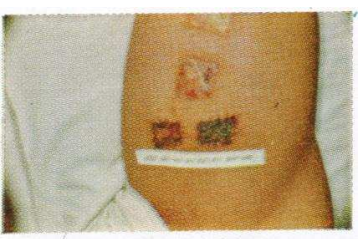

19
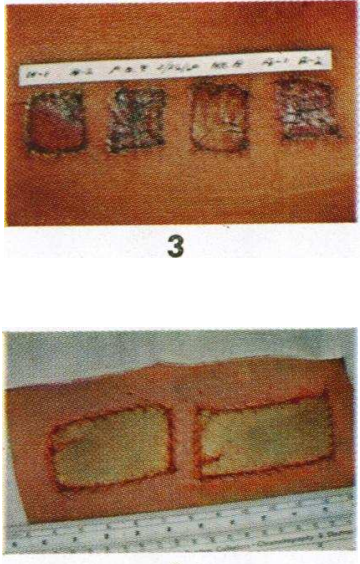

6
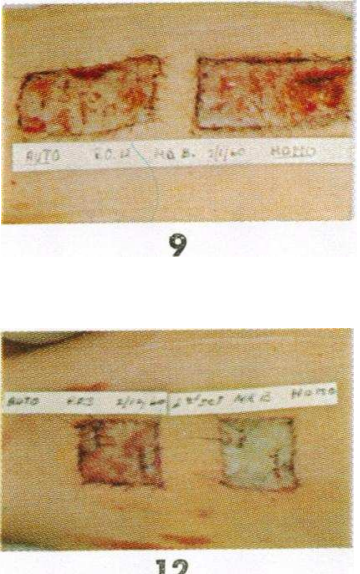

12

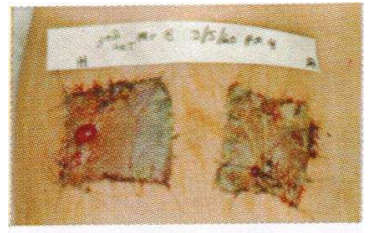

15

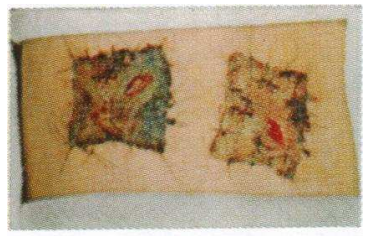

18 
TABLE III

Rejection course of second-set homografts (white grafts)

\begin{tabular}{|c|c|c|c|c|c|}
\hline Subject & $\begin{array}{l}\text { Day grafted } \\
\text { after first set }\end{array}$ & $\begin{array}{l}\text { First day of } \\
\text { vascularization }\end{array}$ & $\begin{array}{l}\text { First day } \\
\text { of edema }\end{array}$ & $\begin{array}{c}\text { Day of } \\
\text { termination }\end{array}$ & $\begin{array}{l}\text { Type of } \\
\text { healing }\end{array}$ \\
\hline V.R. & 19 & 4 & 5 & 7 & $\begin{array}{l}\text { Eschar, } \\
\text { contracted } \\
\text { scar }\end{array}$ \\
\hline $\begin{array}{l}\text { R.B. } \\
\text { L.H. } \\
\text { C.J. } \\
\text { R.H. } \\
\text { W.S. }\end{array}$ & $\begin{array}{l}19 \\
14 \\
14 \\
14 \\
14\end{array}$ & $\begin{array}{l}\mathbf{W}^{*} \\
\mathbf{W}^{\prime} \\
\mathbf{W}^{\prime} \\
\mathbf{W}^{\prime} \\
\mathbf{W}\end{array}$ & $\begin{array}{l}\text { none } \\
\text { none } \\
\text { none } \\
\text { none } \\
\text { none }\end{array}$ & $\begin{array}{l}\text { vague } \\
\text { vague } \\
\text { vague } \\
\text { vague } \\
\text { vague }\end{array}$ & $\left\{\begin{array}{l}\text { Tan crust, } \\
\text { gradual re- } \\
\text { placement }\end{array}\right.$ \\
\hline
\end{tabular}

* Brief, minimal bleeding on postoperative day 2 , but typical white graft thereafter.

but the remaining two pairs received second grafts on Day 14 as originally planned (Figure 11 ). A difference seemed detectable from this slight timing variation (See Table III). Of the six grafts, four evolved into what we call typical white grafts. Of the first two, one (R.B.) had minimal vascularization for 1 day, then followed the course of the white grafts (Figures 12,13). The other graft (on V.R.) was well vascularized for 2 days, then became edematous and underwent early necrosis.

Although the term "white graft" is helpful in classification, it is not descriptive of this circumstance when the skin is pigmented. A better term is, simply, "avascular graft," but in this paper we will continue to employ the more commonly used term. Biopsy does not result in bleeding (Figure 14), an observation recorded in mice by Stetson and Demopoulos (20). Because of the deficiency of blood vessels, edema is absent both in the early postoperative period and from the later rejection process. The graft maintains a surprisingly normal texture for 6 to 7 days then progressively loses thickness, wastes, and gradually loses its normal turgor.

The healing process here is striking in that all such grafts gradually acquire at most a tan crust as the host tissue seems to overgrow the remaining graft dermis. Little fresh granulation tissue appears, and subsequent initial contracture of the wound is slight (Figure 19). By Day 28 the graft site can deceptively resemble a "take." However, when examined 6 to 12 months later, the scar is contracted in the usual fashion.

Accelerated rejection. The third grafting took place between 28 and 44 days after the first grafting (see Table IV). Vascularization of autografts and homografts paralleled that of the first set in five out of six subjects (Figure 15). These grafts first showed edema between Days 3 and 5 (mean, 4.0) and rejection was completed by Days 7 to 10 (mean, 8.2), giving a rejection span of 4.2 days. After interruption of its blood supply, the graft showed superficial ecchymosis, edema, and escharification of the epidermis (Figures 1618). Again the violence of rejection was an in-

TABLE IV

Rejection course of third-set homografts (accelerated rejection)

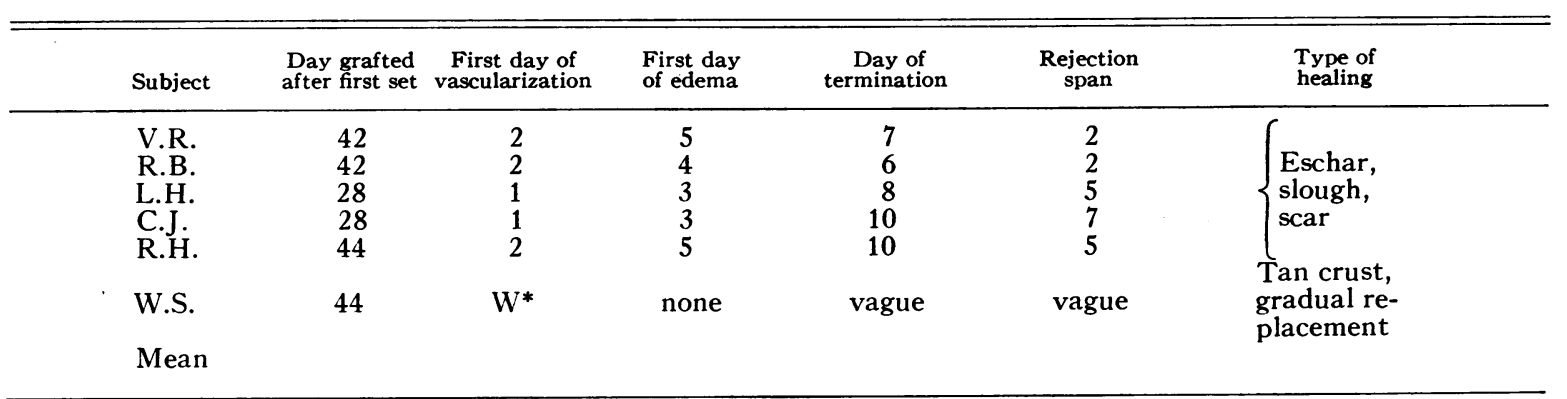

* White-graft rejection, even though graft was placed 44 days after first-set grafting. 
dividual variant. The sixth subject's graft, although placed 44 days after the first set, surprisingly followed a course typical of the white graft, both in rejection pattern and in healing.

Intradermal skin tests. After rejection of the third set of grafts, each subject received intradermal injections of $0.1 \mathrm{ml}$ of plasma containing approximately 2 million donor homologous and autologous peripheral leukocytes. The tests were evaluated 24 hours later. Injections of homologous cells uniformly produced intense erythema surrounding an area of induration greater than $10 \mathrm{~mm}$ in diameter, a reaction interpreted as positive (14). The reaction at injection sites of autologous cells was minimal.

\section{DISCUSSION}

In spite of the patients' ambulatory status, the multiple dressing changes, and the early and continual biopsies of the newly grafted tissue, we believe very little artifact was introduced into the present study. This is substantiated by the low incidence of technical failure of grafting ( 5 per cent), by the minimal gross difference between biopsied and unbiopsied specimens, and by the successful outcome of control autografts (except as noted). It was possible for the pathologist to distinguish readily histological changes attributable to surgery from those of immunologic origin (see Part II of this paper). This is also well described by Medawar in his original work (1).

Skin graft rejection seen in the three pairs of subjects during each of the three sets of grafts follows a generally consistent pattern. The findings agree very well with the data obtained from the laboratory animal and with the few available studies in man. Billingham, Brent, Medawar and Sparrow, using the inbred mouse, found that homograft rejection followed a consistent, reproducible schedule when the genetic relationship of donor and recipient was controlled (18). Grafts from A-strain mice to CBA mice were destroyed in $11.0 \pm 0.3$ days as determined by a histologic grading system based on the amount of surviving epithelium. In contrast, intraspecies grafts in noninbred rats were reported by Billingham and Parkes to undergo gross destruction in anywhere from 9 to 37 or more days (21). By use of the stereomicroscope to determine cessation of capil- lary flow in skin homografts in rats, Taylor and Lehrfeld stated that the mean survival time was 8.1 days for grafts of a constant size (17).

Employing the same technique in man, Converse and Rapaport found the rejection span for first-set grafts to be 7 to 10 days (12). These authors also reported that there was no observable difference in the vascularization and growth of autograft and first-set homografts prior to the onset of rejection, thus confirming the animal work of Medawar (1) and of Taylor and Lehrfeld (17). This work led Rapaport and Converse to the observation in man that a second set of grafts, applied within 14 days after placement of the first set, underwent a special type of accelerated rejection, a phenomenon they termed the "white graft" (15). They postulated that this was a homograft that encountered such an elevated degree of host immunity that not even a transient vascularization took place, an observation also made by Billingham and co-workers (18). Stetson and Demopoulos speculate that the white-graft rejection process might well be mediated by circulating humoral antibodies because of the rapidity with which it occurs (20).

The outstanding value of this study to us is the reproducibility of the correlations made between clinical and microscopic observations. In all slides of first-set grafts, appearance of perivascular mononuclear cell infiltrates coincided to the day with the appearance of edema in the rejecting graft. It is tempting to speculate on the relationship of these two observations. Early damage to the vascular endothelium can be deduced from Converse and Rapaport's (12) and Taylor and Lehrfeld's (17) descriptions of initial capillary dilatation followed by the appearance of multiple small thrombi and rupture of the vessel walls. This process accompanied the observed gross edema.

Stetson and Jensen (22) have shown that circulating cytotoxic antibodies in certain instances can destroy established skin homografts if the antibody can penetrate the vessel wall and make effective contact with the graft tissue. To accomplish this, these authors locally applied xylene to established skin grafts in mice. Such application results in a temporary local increase in vascular permeability, probably due to histamine release. If the animal had previously been injected 
with high-titered homologous cytotoxic antiserum, graft breakdown occurred in the painted area. Because of this effect they postulate a blood-graft barrier that effectively protects the graft from circulating antibody.

If the vascular damage that accounts for the appearance of edema in the first-set grafts is related to the perivascular clumps of mononuclear cells which are seen on the same day, one could suspect that the altered vascular permeability was due to a local, delayed hypersensitivity reaction in the vessel wall between sensitized host mononuclear cells and graft endothelium, as described by Brent, Brown and Medawar (23).

Another observation suggests that a humoral antibody acts as an agent in homograft destruction: although the death of the white graft occurs in a presumably highly immune host, there is a conspicuous absence of cellular infiltration of the graft. This is also described by Bauer in his work with white grafts (24). Billingham has shown that serum from rabbits that have rejected two sets of skin homografts, when incubated with dissociated donor epithelial cells, prevents or reduces regrowth of these cells when they are later placed on vascular beds of the original donor (25). Stetson and Demopoulos (20) demonstrated that vigorous immunization of rabbits by injection of spleen cells in adjuvants would uniformly result in the development of the white-graft type of immunity; and indeed in several instances they were able to passively transfer this immunity with the host's serum (20). Perhaps it is only in the highly immune state associated with white-graft rejection that there is sufficient unbound cytotoxic antibody to be passively transferred. In our own series we did not assay the recipient's serum for hemagglutinating or leukocyte agglutinating activity or attempt passive transfer of immunity. However, as shown by Amos and Day, these various properties of serum need not go hand in hand (26).

Other investigators have reported findings that may be similar to our observation that the gross architecture of the white graft is peculiarly preserved during the graft death, a characteristic that we postulate may be related to the hyperimmune state just discussed. Niven in 1929 (27) discovered that, in in vitro cultures of mouse tissue treated with rabbit immune serum, cell death was associated with autolysis; however, when the cultures were exposed to high-titer hyperimmune serum, there was a qualitative change in the cell death represented by a "fixing" of the cells and inhibition of autolysis, although the serum antibodies used in Niven's work were of heterologous origin. As Stetson and Demopoulos point out (20), white-graft rejection is similar to heterograft rejection between guinea pigs and rabbits, a process known to be mediated by humoral antibodies.

Amos has noted that, in hyperimmune mice, subcutaneous implants of donor homologous skin appear as static structures with absence of surrounding inflammation (28). The fact that the white grafts in our series initially showed little wound contracture might be explained by persistence of the graft dermal pad. Billingham and Medawar have shown that full-thickness defects in skin are repaired by both contracture and true "intussusceptive" growth of encroachment of remaining skin [either islands of epithelial remnants or the epidermis at the periphery of the wound (29)]. This latter phenomenon reduces wound contracture. McKhann demonstrated that, at the height of homograft epidermal destruction, the dermal pad actually increases its adherence to the host bed (30). Presumably, even in a highly immune state, host fibroblasts find the graft dermis an acceptable framework on which to proliferate. McKhann further demonstrated that this dermal pad could be preserved for protracted periods so long as it was protected from dehydration by either graft epidermis or occlusive dressing. Since the white-graft epidermis is not violently sloughed off as is the epidermis in accelerated rejection, perhaps the dermal pad of the white graft is allowed a more successful union with the graft bed. When observed 1 year later, the scar area of the white graft seemed to equal that of other types of rejection processes.

As mentioned above, ecchymosis in the graft is probably the result of both surgical trauma and individual variation in capillary fragility (Figures 6 and 7). Any immediate postoperative nutritional impairment of a graft was manifest by early superficial epithelial desquamation. This would result from inadequate immobilization, bleeding from the graft bed, or excessive graft thickness. The difference in antigenic composition of our 
subjects seems to be the most logical explanation for certain variations encountered. The production of a white graft (in W.S.) 44 days after firstset placement suggests both marked antigenic disparity between donor and recipient and an unusual persistence of the hyperimmune state. The converse of this was seen in Subject V.R.; even though his second-set graft was placed 19 days after the first, only an accelerated rejection was obtained. More recently Bauer has shown in the guinea pig that white grafts may be produced 10 to 12 weeks after the first-set graft has been rejected (24). This illustrates not only individual variation but also marked species variation in the immune response. As can be seen from Table I there was no correlation between donor and recipient blood groups and the ability to elicit transplantation immunity. Postoperative testing of the subjects' serum for epidermal antinuclear antibodies, as described by Bardawil, Toy, Galins and Bayles (31), was uniformly negative. At no time did significant regional adenopathy appear in our subjects.

\section{CONCLUSIONS}

In this study the rejection process of skin homografts has been followed by daily photographs and biopsies in three pairs of healthy, ambulatory volunteers.

In 42 separate grafts there were two surgical failures. The use of autograft controls and unbiopsied duplicate homografts allowed reliable evaluation of changes due to surgical trauma.

The first appearance of bleeding on biopsy was the most reliable sign of establishment of vascularization of a graft, and occurred at mean times of 2.8 days for first-set grafts and 1.6 days for grafts undergoing accelerated rejection. In these grafts the reappearance of edema (after the postoperative edema had subsided) correlated well with the microscopic appearance in the graft of perivascular mononuclear cells. The relationship of these two factors to possible circulating antibody is discussed.

Second-set grafts placed within 14 days after first-set grafting uniformly produced white grafts. These grafts undergo a destruction process that is qualitatively different from the ischemic death that occurs in accelerated rejections. The white graft is never vascularized, and therefore there is no edema in the rejection process. The gross architecture of the graft is peculiarly preserved, and at most a soft tan crust appears which makes it difficult to determine the end point of rejection. Scar contracture is initially minimal but 1 year later appears to be identical with that of accelerated rejection. The possible explanations for the above observations are discussed in the light of other reports that demonstrate the role of hyperimmune cytotoxic antiserum in producing similar graft death. Because of this hospital's active interest in the clinical application of organ transplantation $(32,33)$, the experimental data that are presented have been of value in assessing the status of therapeutic homotransplantation.

By means of the gross criteria established in this report, and the surgical methods described, we have subsequently performed over 90 separate grafts that have further substantiated these data. The histological findings are described and discussed in Part II of this report.

\section{ACKNOWLEDGMENTS}

Dr. J. Walden Retan gave us much invaluable help during this work. We wish to thank Miss Audrey Clemens for her assistance at all the surgical procedures and her interest in the comfort and well being of the volunteers during this study. The sutures used throughout this study were manufactured by Ethicon Inc., Somerville, N. J. We are grateful to Ethicon for assistance in the publication of this manuscript, particularly with reference to defraying the cost of the illustrations.

\section{REFERENCES}

1. Medawar, P. B. The behaviour and fate of skin autografts and skin homografts in rabbits. J. Anat. (Lond.) 1944, 78, 176.

2. Medawar, P. B. A second study of the behaviour and fate of skin homografts in rabbits. J. Anat. (Lond.) 1945, 79, 157.

3. Holman, E. Protein sensitization in isoskingrafting: Is the latter of practical value? Surg. Gynec. Obstet. 1924, 38, 100.

4. Woglom, W. H. Immunity to transplantable tumors. Cancer Rev. 1929, 4, 129.

5. Dammin, G. J., Couch, N. P., and Murray, J. E. Prolonged survival of skin homografts in uremic patients. Ann. N. Y. Acad. Sci. 1957, 64, 967.

6. Kay, G. D. Prolonged survival of a skin homograft in a patient with very extensive burns. Ann. N. Y. Acad. Sci. 1957, 64, 767. 
7. Gibson, T., and Medawar, P. B. The fate of skin homografts in man. J. Anat. (Lond.) 1942, 77, 299.

8. Good, R. A., Varco, R. L., Aust, J. B., and Zak, S. J. Transplantation studies in patients with agammaglobulinemia. Ann. N. Y. Acad. Sci. 1957, 64, 882.

9. Green, I., Inkelas, M., and Allen, L. B. Hodgkin's disease: A maternal-to-foetal lymphocyte chimaera? Lancet $1960,1,30$.

10. Green, I., and Corso, P. F. A study of skin homografting in patients with lymphoma. Blood 1959, 14, 235.

11. Kelly, W. D., Lamb, D. L., Varco, R. L., and Good, R. A. An investigation of Hodgkin's disease with respect to the problem of homotransplantation. Ann. N. Y. Acad. Sci. 1960, 87, 187.

12. Converse, J. M., and Rapaport, F. T. The vascularization of skin autografts and homografts: An experimental study in man. Ann. Surg. 1956, 143, 306.

13. Rapaport, F. T., Thomas, L., Converse, J. M., and Lawrence, H. S. The specificity of skin homograft rejection in man. Ann. N. Y. Acad. Sci. 1960, 87, 217.

14. Merrill, J. P., Friedman, E. A., Wilson, R. E., and Marshall, D. C. The production of "delayed type" cutaneous hypersensitivity to human donor leukocytes as a result of the rejection of skin homografts. J. clin. Invest. 1961, 40, 631.

15. Rapaport, F. T., and Converse, J. M. The immune response to multiple-set skin homografts: An experimental study in man. Ann. Surg. 1958, 147, 273.

16. Friedman, E. A., Bardawil, W. A., Merrill, J. P., and Hanau, C. "Delayed" cutaneous hypersensitivity to leucocytes in disseminated lupus erythematosus. New Engl. J. Med. 1960, 262, 486.

17. Taylor, A. C., and Lehrfeld, J. W. Definition of survival time of homografts. Ann. N. Y. Acad. Sci. 1955, 59, 351.

18. Billingham, R. E., Brent, L., Medawar, P. B., and Sparrow, E. M. Quantitative studies on tissue transplantation immunity. I. The survival times of skin homografts exchanged between members of different inbred strains of mice. Proc. roy. Soc. B 1954, 143, 43.
19. Scothorne, R. J. Lymphatic repair and the genesis of homograft immunity. Ann. N. Y. Acad. Sci. 1958, 73, 673.

20. Stetson, C. A., Jr., and Demopoulos, R. Reactions of skin homografts with specific immune sera. Ann. N. Y. Acad. Sci. 1958, 73, 687.

21. Billingham, R. E., and Parkes, A. S. Studies on the survival of homografts of skin and ovarian tissue in rats. Proc. roy. Soc. B 1955, 143, 550.

22. Stetson, C. A., and Jensen, E. Humoral aspects of the immune response to homografts. Ann. N. Y. Acad. Sci. 1960, 87, 249.

23. Brent, L., Brown, J., and Medawar, P. B. Skin transplantation immunity in relation to hypersensitivity. Lancet $1958,2,561$.

24. Bauer, J. A., Jr. Histocompatibility in inbred strains of guinea pigs. Ann. N. Y. Acad. Sci. 1958, 73 663.

25. Billingham, R. E. Studies on epidermal cell suspensions, with particular reference to problems of transplantation immunity. Ann. N. Y. Acad. Sci. 1957, 64, 799.

26. Amos, D. B., and Day, E. D. Passive immunity against four mouse leukoses by means of isoimmune sera. Ann. N. Y. Acad. Sci. 1957, 64, 851.

27. Niven, J. S. F. The action of cytotoxic antiserum on tissue cultures. J. Path. Bact. 1929, 32, 527.

28. Amos, D. B. Personal communication.

29. Billingham, R. E., and Medawar, P. B. Contracture and intussusceptive growth in the healing of extensive wounds in mammalian skin. J. Anat. (Lond.) 1955, 89, 114.

30. McKhann, C. F. Studies of the dermis in skin homografts. Ann. Surg. 1960, 152, 284.

31. Bardawil, W. A., Toy, B. L., Galins, N., and Bayles, T. B. Disseminated lupus erythematosus, scleroderma, and dermatomyositis as manifestations of sensitization to DNA-protein. I. Immunohistochemical approach. Amer. J. Path. 1958, 34, 607.

32. Murray, J. E., Merrill, J. P., and Harrison, J. H. Kidney transplantation between seven pairs of identical twins. Ann. Surg. 1958, 148, 343.

33. Merrill, J. P., Murray, J. E., Harrison, J. H., Friedman, E. A., Dealy, J. B., Jr., and Dammin, G. J. Successful homotransplantation of the kidney between nonidentical twins. New Engl. J. Med. $1960,262,1251$ 